\title{
IMPLEMENTASI ALGORITMA NAÏVE BAYES DALAM PENENTUAN RATING BUKU
}

\author{
Muthia Anggraini, Rizki Ayuning Tyas, Ismi Ana Sulasiyah, Qurrotul Aini \\ Sistem Informasi, Fakultas Sains dan Teknologi, Universitas Islam Negeri Syarif Hidayatullah Jakarta, \\ Jl. Ir H. Juanda No.95, Cemp. Putih, Kec. Ciputat, Kota Tangerang Selatan, 15412 \\ Email: muthia.anggraini17@mhs.uinjkt.ac.id, rizki.ayuning17@mhs.uinjkt.ac.id, \\ ismi.ana17@mhs.uinjkt.ac.id, qurrotulaini@uinjkt.ac.id
}

(Diterima: 29 Juni 2020, direvisi: 9 Agustus 2020, disetujui: 12 Agustus 2020)

\begin{abstract}
Books are one of the most widely used objects in daily life. With the development of the times, there are other alternatives that can be used to read books without having to buy books in stores. One alternative is the website www.goodreads.com where the website provides a variety of books. On the website, we can also give ratings and review s of books that we have read. These review $s$ and ratings can provide a reference for readers. For this reason, an analysis of book rating is required based on data obtained from the www.kaggle.com website. By processing the data obtained will find the best book viewed from several aspects. The purpose of this research is to determine the rating of a book as a reference for readers in choosing the appropriate book. In this study using a classification algorithm naïve bayes data mining. This research was assisted by rapidminer and Python tools as tools to manage data. The results obtained are the results of determining the book rating using the naive bayes method having an accuracy of $66.98 \%$, precision $74.47 \%$ and recall $62.47 \%$ and the results of this analysis are obtained from the dataset available on the website www.kaggle.com showing that the majority book rating predictions tend to be low.
\end{abstract}

Keywords: book rating, mining, nä̈ve bayes, pyhton, rapidminer

\begin{abstract}
ABSTRAK
Buku merupakan salah satu benda yang paling banyak digunakan dalam kehidupan sehari-hari. Dengan berkembangnya zaman, ada alternatif lain yang bisa digunakan untuk membaca buku tanpa harus membeli buku ditoko. Salah satu alternatifnya adalah website www. goodreads.com yang dimana website tersebut menyediakan berbagai macam buku. Di website tersebut, kita juga dapt memberikan rating dan review buku yang telah kita baca. Review dan rating ini bisa memberikan acuan bagi para pembaca. Untuk itu diperlukan nya analisis terhadap penentuan rating buku berdasarkan data yang didapatkan dari situs www.kaggle.com. Dengan mengolah data yang didapatkan akan mengetahui buku yang paling terbaik dilihat dari beberapa segi. Adapun tujuan dilakukan penelitian ini adalah untuk menentukan rating dari sebuah buku sebagai acuan pembaca dalam memilih buku yang sesuai. Dalam penelitian ini menggunakan algoritma klasifikasi data mining nä̈ve bayes. Penelitian ini dibantu oleh tools rapidminer dan Python sebagai alat bantu mengelolah data. Hasil yang diperoleh adalah hasil penentuan rating buku menggunakan metode naïve bayes memiliki accuracy 66,98\%, precision $74,47 \%$ dan recall $62,47 \%$ dan hasil analisis ini di dapatkan dari dataset yang ada pada situs $\underline{w w w . k a g g l e . c o m}$ menunjukan bahwa mayoritas prediksi rating buku cenderung rendah.
\end{abstract}

Kata Kunci: rating buku, mining, nä̈ve bayes, python, rapidminer

\section{PENDAHULUAN}

Menurut Kamus Besar Bahasa Indonesia, Buku adalah lembar kertas yg berjilid, berisi tulisan atau kosong [1]. Buku adalah kumpulan kertas atau bahan lainnya yang dijilid menjadi satu pada salah satu ujungnya dan berisi tulisan atau gambar [1]. Setiap sisi dari sebuah lembaran kertas pada buku disebut sebuah halaman. Banyak jenis-jenis buku yaitu, majalah, novel, komik, kitab suci, dan juga naskah. Seiring dengan perkembangan dalam bidang dunia informatika, kini dikenal pula istilah $e$ book (buku elektronik), yang mengandalkan perangkat seperti komputer meja, komputer jinjing, 
komputer tablet, telepon seluler dan lainnya, serta menggunakan perangkat lunak tertentu untuk membacanya. Buku cetak pada umumnya terdiri atas setumpuk kertas dijilid yang berisi teks atau gambar, maka buku elektronik berisikan informasi digital yang dapat berisi teks, gambar, audio, video.

Pada era sekarang, untuk membaca buku tidaklah harus membeli ditoko buku. Sekarang sudah banyak platform atau website yang menyediakan untuk bisa membaca buku secara berbayar ataupun gratis dan buku tersebut tidak perlu digenggam atau dipegang oleh kita. Cukup dengan membawa handphone ataupun perangkat keras lainnya yang bisa terhubung dengan internet, maka kita dapat membaca buku. Salah satunya adalah website dari www.goodreads.com yang menyediakan bacaan buku novel yang bisa dibaca secara online dan gratis. Tapi tidak semua buku bisa dibaca disana, walau begitu cukup banyak buku yang tersedia disana. Selain bisa membaca, disana kita juga bisa memberikan review dan rating untuk setiap buku yang kita baca. Review dan rating ini bisa menjadi masukan untuk para penulis buku tersebut.

Data mining merupakan sebuah metode yang digunakan dalam pengolahan data berskala besar oleh karena itu data mining memiliki peranan yang sangat penting dalam beberapa bidang kehidupan diantaranya yaitu bidang industri, bidang keuangan, cuaca, ilmu dan teknologi. Data mining juga bisa diartikan sebagai rangkaian kegiatan untuk menemukan pola yang menarik dari data dalam jumlah besar, kemudian data - data tersebut dapat disimpan dalam database, data warehouse atau penyimpanan informasi [7].

Salah satu teknik yang dibuat dalam data mining adalah adalah bagaimanana menelusuri data yang ada untuk membangun sebuah model, kemudian menggunakan model tersebut agar dapat mengenali pola data yang lain yang tidak berada dalam basis data yang tersimpan. Dalam data mining, pengelompokan data juga bisa dilakukan. Tujuannya adalah agar kita dapat mengetahui pola universal data-data yang ada. Ada beberapa teknik yang dimiliki data mining berdasarkan tugas yang bisa dilakukan, yaitu [8]: Pertama, klasifikasi. Dalam klasifikasi, terdapat target variabel kategori. Dalam klasifikasi variabel, tujuan bersifat kategorik. Misalnya, kita akan mengklasifikasikan pendapatan dalam tiga kelas, yaitu pendapatan tinggi, pendapatan sedang, dan pendapatan rendah. Kedua, clustering. Clustering dapat dipakai untuk memberikan label pada kelas data yang belum diketahui. Clustering lebih ke arah pengelompokan record, pengamatan, atau kasus dalam kelas yang memiliki kemiripan. Ketiga, asosiasi. Asosiasi adalah teknik mining untuk menemukan asosiatif antara kombinasi atribut. Mengidentifikasi hubungan antara berbagai peristiwa yang terjadi pada satu waktu.

Salah satu metode klasifikasi dari data mining adalah naive bayes. Nä̈ve bayes merupakan sebuah pengklasifikasian probabilistik sederhana yang menghitung sekumpulan probabilitas dengan menjumlahkan frekuensi dan kombinasi nilai dari dataset yang diberikan [9]. Algoritma mengunakan teorema Bayes dan mengasumsikan semua atribut Independen atau tidak saling ketergantungan yang diberikan oleh nilai pada variabel kelas [10]. Keuntungan penggunaan Nä̈ve bayes adalah bahwa metode ini hanya membutuhkan jumlah data pelatihan (Training Data) yang kecil untuk menentukan estimasi parameter yang diperlukan dalam proses pengklasifikasian. Nä̈ve bayes sering bekerja jauh lebih baik dalam kebanyakan situasi dunia nyata yang kompleks dari pada yang diharapkan [11].

Untuk menganalisis review dan rating yang sudah ada, kita bisa mengimplementasikan salah satu metode dari data mining, yaitu nä̈ve bayes. Metode nä̈ve bayes ini digunakan untuk mengklasifikasikan beberapa informasi sejenis menjadi satu kesatuan. Metode nä̈ve bayes adalah metode yang mempunyai tingkat kesalahan yang sangat minimum jika dibandingkan algoritma klasifikasi lainnya [2]. Walaupun memiliki tingkat kesalahan yang sangat minumum, metode naïve bayes ini memiliki kekurangan yaitu rendahnya tingkat kepekaan terhadap data yang hilang atau missing value. Oleh karena itu tetap diperlukan pengukuran tingkat ke akuratan untuk perhitungan dengan menggunakan data ini dengan cara confusion matrix.

Pada penelitian ini akan dilakukan penelitian menggunakan metode naïve bayes yang dibantu oleh software rapidminer. Yang dimana kami melakukan penelitian ini untuk menentukan prediksi rating buku yang terdapat di www.goodreads.com. Berdasarkan permasalahan yang telah dipaparkan sebelumnya, adapun tujuan dilakukan penelitian ini adalah untuk menentukan rating dari sebuah buku sebagai acuan pembaca dalam memilih buku yang sesuai pada website www.goodreads.com. Peneliti menggunakan data "books listed in goodreads" yang didapat dari situs www.kaggle.com. Hasil akhir yang diberikan berupa hasil rating menggunakan metode nä̈ve bayes. 


\section{TINJAUAN PUSTAKA}

Berdasarkan hasil penelitian sebelumnya [3], penelitian ini membahas tentang bagaimana mengimplementasikan disiplin ilmu data mining menggunakan komparasi metode naïve bayes dengan algoritma C4.5 yang merupakan sebuah metode untuk melakukan teknik klasifikasi serta diaplikasikan dengan tools rapidminer. Penelitian ini memperoleh hasil bahwa dengan pemilihan data training 50 record, 4 atribut predictor dan 1 atribut target menghasilkan 5 aturan dalam pohon keputusan sehingga aturan tersebut dapat digunakan dalam menentukan kelulusan tepat waktu pada mahasiswa STMIK STIKOM BALI. Hasil analisis menggunakan metode nä̈ve bayes diperoleh hasil akurasinya sebesar $89,27 \%$ dimana hasil performance akurasi menunjukan kelulusan tepat waktu sebanyak 40 dan tidak tepat 10 .

Pada penelitian selanjutnya yang berkaitan dengan penelitian ini menyatakan bahwa dengan adanya review terhadap sebuah film bisa membantu penonton untuk lebih selektif lagi dalam memilih suatu film. Dan dari pihak produksi bisa terbantu untuk mengukur seberapa jauh kualitas film yang mereka hasilkan. Penelitian tersebut menunjukan bahwa pihak produksi sendiri terkadang mengalami kesulitan dalam memilah dan mengkategorikan review, apakah produk tersebut kualitasnya tergolong bagus, cukup bagus, tidak bagus, dan lainnya. Dalam penelitian in penilaian suatu film berdasarkan review yang telah diberikan rating. Penelitian menggunakan metode klasifikasi nä̈ve bayes yang dimana hasil klasifikasi yang didapat tersebut kemudian dihitung nilai accuracy, precision, recall. Yang dimana accuracy 55,80\%, precision $32,41 \%$ dan recall $46,70 \%$. Pada penelitian ini hasil untuk naïve bayes pada model distribusi untjk nilai class "RENDAH" sebanyak 0,707, sedangkan class "TINGGI" sebanyak 0,293, menunjukan penentuan rating film (imdb_score) tinggi apabila tahun film (title_year) baru serta duration film panjang [4].

Mengacu pada penelitian berikutnya [5] yang membahas tentang pengklasifikasian teks otomatis pengaduan dan pelaporan masyarakat yang ada di Kepolisian Negara Republik Indonesia menggunakan metode nä̈ve bayes classifier. Yang menjadi probabilitas kata kunci dalam penelitian ini adalah membandingkan dokumen latih dan dokumen uji. Keduanya dibandingkan dengan beberapan tahapan persamaan yang pada akhirnya akan diperoleh hasil tertinggi untuk ditetapkan sebagai kategori dokumen baru. Untuk hasil penelitian ini, pengklasifikasian teks otomatis pelaporan dan pengaduan masyarah menghasilkan rata-rata akurasi yang tinggi, yaitu dengan recall 93\%, precission $90 \%$, dan $f$-measure $92 \%$.

Penelitian lainnya [6] membahas bagaimana algoritma naïve bayes dapat membantu untuk memprediksikan angka kelahiran. Penelitian ini dilakukan didaerah Medan tepatnya di Kabupaten Batubara yang dimana terdiri dari 10 dusun. Tujuan penelitian ini adalah melihat pola prediksi dari setiap atribut-atribut yang terdapat pada dataset dengan menggunakan algoritma naïve bayes. Penelitian ini dibantu dengan bahasa pemrograman visual basic 2008 serta microsoft access 2007 sebagai basis data. Hasil dari penelitian ini adalah mempermudah pihak kantor desa lalang dalam proses pengelolaan data penduduk, membantu dalam proses penginputan data, pencarian data dan laporan penduduk.

Pada penelitian ini, akan dilakukan penentuan rating dari sebuah buku yang akan dijadikan acuan pembaca dalam memilih buku yang sesuai. Berdasarkan beberapa penelitian sebelumnya, implementasi algoritma naïve bayes digunakan untuk mengklasifikasikan data menjadi beberapa kelas. Peneliti menggunakan metode naïve bayes karena metode ini membantu penelitian ini dalam mengklasifikasikan rating dari sebuah buku. Penelitian ini dibantu dengan menggunakan software rapidminer dan Python versi 3.7 yang mempermudah dalam mengklasifikasikan dataset yang digunakan.

\section{METODE PENELITIAN}

Berikut adalah uraian metode yang digunakan selama penelitian. Selama penelitian ini berlangsung terdapat 2 metode yang digunakan, yaitu metode untuk pengumpulan data dan metode untuk pengelolaan data.

Pengumpulan data dalam penelitian ini diambil berdasarkan data-data sampel dari situs internet, yaitu situs www.kaggle.com. Data yang didapatkan adalah data berupa data statistik bukubuku pada website www.goodreads.com. Data yang terkumpul sebanyak 11.127 yang terdiri dari atribut bookID, title. author, average_rating, isbn, isbn13, language_code, num_pages, rating_count, 
text_review_count, publication_date, publisher yang kemudian akan diolah kembali sesuai dengan batasan atau ketentuan penelitian.

Pada penelitian ini, pengolahan data dilakukan dengan menggunakan bantuan tools berupa software rapidminer, yang dimana rapidminer adalah salah satu software untuk melakukan pengolahan data mining. Selain rapidminer, pengolahan data juga dibantu dengan bahasa pemrograman Pyhton. Langkah-langkah yang dilakukan dalam pengolahan data adalah sebagai berikut:

\section{Selection}

Tahapan ini bertujuan untuk pemilihan dataset yang akan digunakan dalam penelitian ini. Data yang dipilih harus sesuai dengan batasan yang sudah ditentukan di dalam penelitian ini berupa data yang digunakan data selama beberapa tahun dimulai dari $1900-2019$. Dalam tahapan ini dataset yang dimiliki akan dibagi menjadi data training dan data testing. Data training adalah data yang digunakan untuk perhitungan probabilitas dari data berdasarkan data pembelajaran yang dilakukan. Sedangkan data testing merupakan data yang akan atau sedang terjadi dan dipergunakan sebagai bahan uji yang sebelumnya sudah didapatkan pada data training.

2. Pre-Processing

Tahapan pre-processing dilakukan karena ketika data dimasukan kedalam software rapidminer terdapat missing value yang berarti data yang didapat belum normal. Kemudian didalam tahapan pre-processing ini dilakukan tahap untuk mengurangin atribut-atribut yang masih terdapat missing value dengan tahapan transformasi yang dilakukan dengan software rapidminer.

3. Data Mining

Pada penelitian ini, proses data mining dilakukan menggunakan metode naïve bayes untuk melakukan proses analisis pada dataset "books listed in goodreads" yang didapat di situs www.kaggle.com. Tahapan ini adalah tahapan dimana dilakukannya proses training pada data-data yang akan digunakan, dengan tujuan untuk membuat melatih model algoritma yang akan digunakan untuk data testing.

4. Pengujian Model dan Evaluation

Tahapan ini adalah tahapan dimana data yang sudah melalui proses pelatihan (training) akan ditentukan akurasi kualitas datanya sekaligus melakukan testing terhadap model yang telah dibuat. Dengan menggunakan metode confusion matrix, data yang dimana tidak digunakan untuk training akan digunakan menjadi data test untuk dilakukannya testing terhadap model algoritma yang sudah dibuat sekaligus menentukan akurasi dari hasil analisis. Yang dimana untuk pengujian Accuracy, Precission, Re-call agar bisa membuktikan kinerja metode nä̈ve bayes menggunakan persamaan sebagai berikut [12]:

a. Accuracy

$$
\text { Accuracy }=\frac{(T P+T N)}{(T P+F P+T N+F N)} \times 100 \%
$$

b. Precission

$$
\text { Precission }=\frac{T P}{T P+F P} \times 100 \%
$$

c. Re-call

$$
\text { Recall }=\frac{T P}{T P+F N} \times 100 \%
$$




\section{HASIL DAN PEMBAHASAN}

Berikut adalah hasil pengolahan data yang telah dikerjakan, sebagai berikut:

\subsection{Hasil Selection}

Dataset yang digunakan adalah dataset "books listed in goodreads" yang diambil dari website www.kaggle.com. Selama tahun 1900-2019, dalam dataset ini diberikan jumlah sebanyak 11.127 buku. Adapun atribut yang digunakan pada penelitian ini terbagi menjadi dua jenis variabel, antara lain;

1. Variabel Dependen $(\mathrm{Y})$

Variabel ini disebut juga dengan nilai yang terikat. Variabel $\mathrm{Y}$ dalam penelitian ini adalah average_rating dimana variabel ini merupakan nilai untuk memprediksi rating buku.

2. Variabel Independen $(\mathrm{X})$

Variabel ini merupakan variabel dengan nilai yang tidak bergantung dengan variabel lainnya. Variabel ini bisa disebut juga variabel yang kehadirannya dibutuhkan oleh variabel terikat. Nilai class untuk variabel $\mathrm{X}$ dapat dilihat pada Tabel 1.

\section{Tabel 1. Nilai Class Untuk Setiap Atribut}

\begin{tabular}{lll}
\hline No. & Nama Atribut & Class \\
\hline 1 & bookID & Integer \\
2 & Title & Text \\
3 & Author & Text \\
4 & Isbn & Integer \\
5 & isbn13 & Integer \\
6 & language_code & Text \\
7 & num_pages & Tinggi $\geq 1000$, Sedang $\geq 500$, Rendah $<500$ \\
8 & rating_counts & Tinggi $\geq 100000$, Sedang $\geq 10000$, Rendah $<10000$ \\
9 & text_review_count & Tinggi $\geq 5000$, Sedang $\geq 500$, Rendah $<500$ \\
10 & publication_date & Text \\
11 & Publisher & Text \\
\hline
\end{tabular}

Dalam tahap ini juga, dataset akan dibagi menjadi data training dan data testing. Training-Set ini akan digunakan untuk membuat model machine learning, sedangkan Test-Set akan digunakan untuk menguji performa dan kebenaran (terhadap korelasi) dalam model yang bersangkutan. Metode yang digunakan untuk pembagian ini menggunakan peneliti menggunakan Python versi 3.7 dengan membagi data yang telah dimuat menjadi dua berdasarkan ukuran standar pembagian dataset yaitu, $80 \%$ diantaranya akan digunakan untuk melatih model dan $20 \%$ digunakan untuk data validasi. Tabel 2 dan Tabel 3 masing-masing menunjukan potongan hasil dari pembagian kedua data ini. 
Tabel 2. Data Training Dengan Jumlah Data 8901

\begin{tabular}{|c|c|c|c|c|c|c|c|c|c|}
\hline averape int. & bookil: & tibe & authers & inte & istents: & monagec. & murnigages & ratings_count & texturiv \\
\hline 40 & 14492 & Fartuelitos & Leen sciaht & 1se9backat & 2 rs15ae $\cdot 12$ & eng & 299 & 63 & 3 \\
\hline 188 & 4135 & Hane res the & Amy Sedanta & 44estae43 & 3 TBOAsE +12 & $\operatorname{mg}$ & 304 & अ2se & 1401 \\
\hline 48 & mats & The Listaner. & Anconinoual. & moatmo & ม Ta193e $\cdot 12$ & eng & $n$ & $x$ & 3 \\
\hline 414 & 17245 & Hecere the P. & Dada R Ces. & 243431 teas & 2780T $4 E \cdot 12$ & eng & 60 & 332 & $3 e$ \\
\hline 384 & $314 a d$ & Ruby the Rad. & Daisy Ueado. & $0.43273061 x$ & 2 TEO4te-12 & ends & $6 s$ & 4334 & $3 \pm 9$ \\
\hline 18 & t699 & Shy Unde Os. & Roald Daht & 90044770 & 3 78014E +12 & $\operatorname{mg}$ & $20 a$ & a170 & 620 \\
\hline 241 & 22944 & Drumints sil. & Jo Claphonke. & \#12551243 & A760asE +12 & ence & 399 & t & 0 \\
\hline $3 \geqslant 5$ & Tess & travas & Whast Crich. & sesogose & $3.78005 \mathrm{E} \cdot 12$ & eng & 400 & rost & $3: 4$ \\
\hline 144 & 22344 & The Wyater F - & Grant Uamise. & tse3asta9t & 2 TE156E $\cdot 12$ & $\cos 15$ & so & ess & 40 \\
\hline 398 & 784 & Del amory at. & Gatnei Gard. & $32 r 350444$ & 3 7. 78039E +12 & spa & 176 & 4sea & $27 \mathrm{e}$ \\
\hline 374 & prat & Cartutates o. & Jamestama. & 222012117 & 3) TeoezE: 12 & $\operatorname{ence}$ & 72 & 30 & 9 \\
\hline 247 & 38333 & Loilng wa 8 . & Carcion Meje: & 132004510 & 3 .70015E $\cdot 12$ & eng & 265 & 1381 & 196 \\
\hline 435 & 35720 & Lover Elanal - & JR. Wand & 451219043 & S reouse +12 & eng & 464 & 15834 & sazs \\
\hline
\end{tabular}

Tabel 3. Data Testing Dengan Jumlah Data 2226

\begin{tabular}{|c|c|c|c|c|c|c|c|c|c|c|}
\hline amerage fat. & nowkib & ste & nuthors & isten & isten13 & lanouage.c. & man saves & ratings_count & \multicolumn{2}{|c|}{ texturer } \\
\hline 263 & 33096 & Thuteen Wod. & Chanes Fraser & $27550932 t$ & 9.7803aE +12 & ing & 422 & 10534 & 1578 & $\hat{n}$ \\
\hline 243 & 1400 & Waseltey & Walter Bcen. & 1020อ6อ13 & 9.7wotac +12 & ang & 463 & 69 & 0 & \\
\hline 43 & 44350 & Bezani Eay. & Francesea LI & 60504357 & 37 .700eE +12 & enus & 304 & 42 & 5 & \\
\hline 29 & 15910 & Censa The - & Jea Coteta & axts701a0x & 27honas +12 & ang & ta & tall & $v$ & \\
\hline 28 & mas & Fragments & Jan Heutnil & 164657973 & 3.7ataue -12 & ang & tall & 127 & 11 & \\
\hline 200 & 24040 & the khoudta: & Cendon Kanth. & 04jasatrix & 2.7HoLAE +12 & ang & 144 & 3906 & 200 & \\
\hline 422 & 13014 & The state of & Sarataw U - & 88171345t & $970085+12$ & eng & $m 0$ & 28 & $t$ & \\
\hline 644 & 36 as & Drap The for & Bill PermanT. & 1502051614 & ota150e+12 & mon & 192 & 955 & 41 & \\
\hline 36 & 7113 & The Neg in th. & Adam Gegne. & 7atองด349 & 97orve+12 & sous & 410 & as & 104 & \\
\hline 287 & 15100 & the Eoleyn in & Paliess Gred. & 74272501 & 271074t+12 & ang & 518 & 68753 & 3904 & \\
\hline 362 & 31178 & Eackwhen - & Anese Thiar & 3457243 & $9700356+12$ & $\operatorname{lng}$ & 396 & 15040 & 1230 & \\
\hline $28 \mathrm{ag}$ & 9590 & Gaลàeagot & Mart Voneegu. & 385393970 & $9.760036 \cdot 12$ & ono & 224 & 55050 & 1900 & \\
\hline 414 & 40424 & Tretan orthe & Edoar Rice 18. & 597559573 & $9.70052 E \cdot 12$ & ang & sta & 29 & 1 & \\
\hline$<$ & 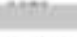 & & & mes= & & & & & 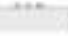 & 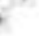 \\
\hline
\end{tabular}

\subsection{Hasil Pre-processing}

Dalam tahap pre-processing ini akan dilakukan identifikasi terhadap data yang tidak konsisten, duplikasi data, dan data yang tidak lengkap (missing value). Proses ini dilakukan dengan seleksi data-data yang tidak konsisten dan penghapusan missing value. Dataset yang dimiliki peneliti tidak memiliki data yang tidak konsisten secara signifikan dan hanya mengurangi sedikit data yang dimiliki menjadi 11.124 baris. Jumlah data yang dimiliki setelah tahap pre-processing ini selanjutnya akan digunakan untuk pembagian data dalam bentuk data training dan data testing.

Setelah membagi data menjadi data training dan data testing, akan dilakukan metode cleaning supaya data yang digunakan valid sesuai kebutuhan. Sehingga dari nilai class data buku dalam atribut tidak terjadi ketidakkonsistenan data dalam pengujian. Lalu data tersebut melalui pengolahan, dalam pengolahan data peneliti menggunakan software rapidminer studio versi 9.6 yang nantinya dapat menghasilkan sebuah prediksi rating buku. Tabel 4 menunjukkan potongan data training sebelum tahap pre-processing, sedangkan Tabel 5 merupakan potongan data training sesudah tahap preprocessing. 
Tabel 4. Data Training Sebelum Pre-Processing

\begin{tabular}{|c|c|c|c|c|c|c|c|c|c|}
\hline average, int. & bocks: & tole & suthors & ate & insents & labouage_c. & num soges & ratings, count & seat ire \\
\hline 40 & 14422 & Favent is 5 . & Leon soand & 1Seseadcat & 9.7B1Sge-12 & eng & 299 & 6 & 3 \\
\hline 188 & 4135 & Whe for the. & Amy Sedahs: & L4557ateas & 97 7adse -12 & ang & 364 & mase & 1401 \\
\hline 48 & 37275 & The Lustaner. & Anshymaut. & 1931047170 & 976 mas-12 & ang & $n$ & $2 b$ & 3 \\
\hline 424 & 17245 & Noces the P & Daud R Geb & 74349458 & $970074 E-12$ & eng & 540 & 332 & $3 t$ \\
\hline $3: 4$ & J14as & Ruby the Rect. & Dairy Ueads & $0409+3600 x$ & 9Tab4aE-12 & nus & 56 & 4334 & 319 \\
\hline 128 & stat & srunde os & Rosid Dahi & 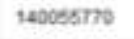 & $97 a b 14 \leq-12$ & ang & $2 \mathrm{~ns}$ & 9870 & 120 \\
\hline 241 & 22244 & Dnum inte Sa. & So Caxtinike. & $\operatorname{ar2s61249}$ & 9 7abe $15 \cdot 12$ & noce & 390 & 1 & 0 \\
\hline $3 \neq 5$ & Tees & Tranels & Michasi Crich. & sososose & 97400SE-12 & ang & 450 & ros & 514 \\
\hline 34 & 22343 & The Ulytery P & Crart Vontso. & 196369test & $978150 e-12$ & nus & as & eate & 45 \\
\hline 338 & 784 & Def ambrr, ot. & Catnel Cardi. & 307250444 & 9 7ana1E -12 & spa & 176 & 4sas & 278 \\
\hline 374 & 17net & Cirturistes a & James Lama. & 322012281 & 9 7abeze-12 & $n$ & $n$ & 30 & $\$$ \\
\hline 247 & 36303 & Loutng wes. & Carth Weje & 152054590 & 7. Tab1se-12 & ang & $2 e s$ & 1361 & 150 \\
\hline 435 & 35720 & iover Elenal - & IR. Kand & astatabas & 97 Touse- 12 & ang & 464 & 195343 & 5325 \\
\hline
\end{tabular}

Tabel 5. Data Training Sesudah Pre-Processing

\begin{tabular}{|c|c|c|c|c|c|c|c|c|c|}
\hline \multirow{2}{*}{$\begin{array}{l}\text { Ogan in } \\
\text { antrage fre }\end{array}$} & \multirow{2}{*}{$\begin{array}{l}\text { Turbe Pras } \\
\text { tine }\end{array}$} & \multirow{2}{*}{$\begin{array}{l}\text { If Aute Modei } \\
\text { aubors }\end{array}$} & \multirow[b]{2}{*}{ intin } & \multirow[b]{2}{*}{ istont3 } & \multirow[b]{2}{*}{ languape. } & \multicolumn{3}{|c|}{ 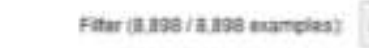 } & \multirow[b]{2}{*}{ nom,pan } \\
\hline & & & & & & putencabion - & pubelsher & bocke & \\
\hline Tnges & farmestos. & Leon Sdaby. & 15aseaso21 & 9) fonsise- 12 & ang & shaven & Paul Dn Botik & 14432 & Randan $\hat{A}$ \\
\hline Renduh & tLine Yau tho. & Amr Sedart & 4457880 & 9 Trouse-12 & eng & taneatios & Wamer toose. & 405 & Randah \\
\hline Tinges & The Listener: & Ananymavel. & 19320 บ170 & 9 Tatgxe +12 & ma & ยrasen & Fallomahpte. & 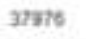 & Rantah \\
\hline Triges & Mecor, The P. & Dadd R Geo. & 7434915aa & 37not $4 E-12$ & $\operatorname{me}$ & 3202006 & Pockut Pooka & 1rass & Sectang \\
\hline Rondan & Ruby the Fed. & Daisy Moate & ova97386tx & 9 Houte-12 & mus & sntabos & Schelaste ine & 314ts & Rendah \\
\hline Runduh & Wh Unda Os. & Roald Dani & 140055870 & 9naote-12 & ang & Stiraas & Fenquie tols. & $\sin$ & Rendah \\
\hline Rantan & Drum into sit. & Jo Claptonkie & enzstias & 9 Tanale-12 & ince & 272004 & Torfartaty & 22944 & Rantah \\
\hline Randan & Tranats & Whatat Cich. & soserose & 3) raoce-12 & ang & 1450002 & Harpceren & $7 s e s$ & Rondah \\
\hline Rendah & The Shatery $P$. & Crant thomso. & 15e3egtan & $9 \operatorname{tans} \theta+12$ & nus & 3nt9as & vectigo & 22349 & Rendah \\
\hline Runduh & Deviancer at. & Gatrel Gad & 30 rasoc44 & 97303te-12 & 200 & $27 \pi 006$ & Pleay fates & 704 & Rendat \\
\hline Rentah & Ciffstioten o. & Jamns Lama. & 022012197 & 9 ranexf +12 & ence & tanstasa & Cifs Notes & 17121 & Randah \\
\hline Findah & Loung wes: & Carolyn Herer & 152054510 & aranse-12 & ang & rataoes & Harcount Chat & 38333 & Rondah \\
\hline Tinggr & Lover Efanal - & JR Wad & 451218043 & F rnouse- 12 & ang & 3raods & Signet & 35720 & Randah \\
\hline $\bar{k}$ & - & 10 & & t.m. & & & & & -3 \\
\hline
\end{tabular}

\subsection{Hasil Data Mining}

Pada penelitian ini, proses data mining dilakukan menggunakan metode naïve bayes untuk melakukan proses analisis pada dataset buku. Gambar 1 merupakan rancangan proses klasifikasi nä̈ve bayes yang dilakukan menggunakan software rapidminer. 


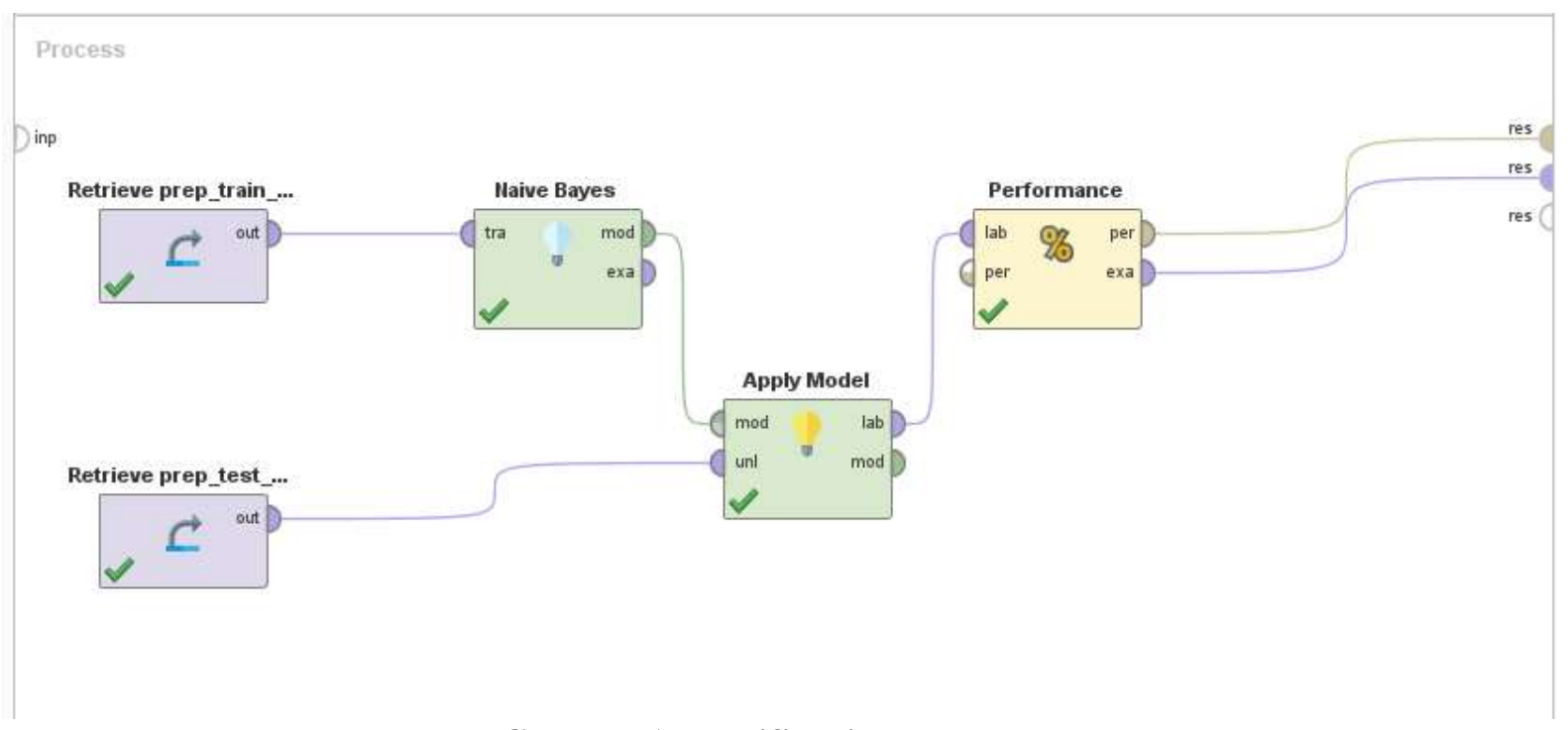

Gambar 1. Klasifikasi Nä̈ve Bayes

\subsection{Hasil Pengujian Model dan Evaluation}

Rapidminer sebagai solusi untuk memprediksi dan menganalisis komputasi statistik [13]. Model yang telah dibentuk diuji tingkat akurasinya dengan memasukkan data uji yang berasal dari data training. Pada Gambar 2 menunjukan distribusi class untuk label atribut average_rating. Hasil pada Gambar 2 menunjukan model distribusi naïve bayes. Pada hasil nä̈ve bayes bisa dilihat bahwa model distribusi nilai class "Tinggi" sebanyak 0,447, sedangkan class "Rendah" sebanyak 0,553.

\section{SimpleDistribution}

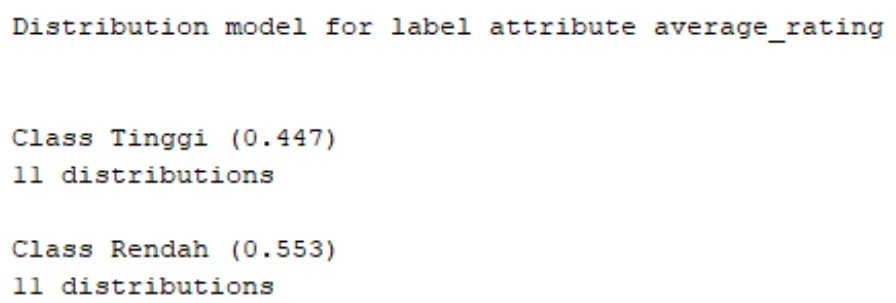

Gambar 2. Model Distribusi Nä̈ve Bayes

Setelah melakukan perhitungan untuk metode naïve bayes, maka kita melakukan metode pengujian untuk akurasi data hasil perhitungan tadi dengan metode confusion matrix. Confusion matrix adalah suatu metode yang biasanya digunakan untuk melakukan perhitungan akurasi pada konsep data mining [14]. Confusion matrix memberikan penilaian performance klasifikasi berdasarkan objek dengan benar atau salah [7]. 
Tabel 6. Tingkat Accuracy, Precision, Recall Pada Nä̈ve Bayes

\begin{tabular}{|c|c|c|c|}
\hline & true Rendah & true Tinggi & class precision \\
\hline pred. Rendah & 779 & 267 & $74.47 \%$ \\
\hline pred. Tinggi & 468 & 712 & $60.34 \%$ \\
\hline class recall & $62.47 \%$ & $72.73 \%$ & \\
\hline
\end{tabular}

Berdasarkan Tabel 6 nilai didapat bahwa accuracy $66.98 \%$, precision $74.47 \%$ dan recall $62.47 \%$. Selain menggunakan rapidminer, untuk menguji nilai tersebut kita juga dapat menghitung nilai accuracy, precision, dan recall secara manual, yaitu sebagai berikut:

1. Accuracy

$$
\begin{aligned}
& \text { Accuracy }=\frac{(T P+T N)}{(T P+F P+T N+F N)} \times 100 \% \\
& \text { Accuracy }=\frac{779+712}{779+267+712+468} \times 100 \% \\
& \text { Accuracy }=0.6698 \times 100 \% \\
& \text { Accuracy }=66.98 \%
\end{aligned}
$$

2. Precission

$$
\begin{aligned}
\text { Precission } & =\frac{T P}{T P+F P} \times 100 \% \\
\text { Precission } & =\frac{779}{779+267} \times 100 \% \\
\text { Precission } & =0.7447 \times 100 \% \\
\text { Precission } & =74.47 \%
\end{aligned}
$$

3. Recall

$$
\begin{aligned}
& \text { Recall }=\frac{T P}{T P+F N} \times 100 \% \\
& \text { Recall }=\frac{779}{779+468} \times 100 \% \\
& \text { Recall }=0.6247 \times 100 \% \\
& \text { Recall }=62.47 \%
\end{aligned}
$$

\section{KESIMPULAN}

Model nä̈ve bayes memiliki tingkat kesalahan yang sangat minimum jika dibandingkan dengan algoritma klasifikasi lainnya. Penelitian yang dilakukan adalah penentuan rating buku. Pada hasil naïve bayes bisa dilihat bahwa model distribusi nilai class "Tinggi" sebanyak 0,447, sedangkan class "Rendah" sebanyak 0,553. Hasil penelitian menentukan bahwa hasil penentuan rating buku menggunakan metode nä̈ve bayes memiliki accuracy $66.98 \%$, precision $74.47 \%$ dan recall $62.47 \%$. Berdasarkan hasil penelitian yang didapatkan menggunakan dataset dari situs https://kaggle.com/ menunjukan bahwa rating buku pada data testing sebanyak 2226 data mayoritas prediksi rating buku cenderung rendah. Untuk penelitian selanjutnya, disarankan untuk menggunakan variable yang lainnya yang bisa menjadi bahan pertimbangan dan menggunakan metode data mining 
lainnya seperti Decision Trees, atau Neural Network agar bisa menjadi pembanding untuk metode naïve bayes.

\section{REFERENSI}

[1] H. Alwi, Kamus Besar Bahasa Indonesia, 3rd ed. Jakarta: Balai Pustaka, 2007.

[2] J. Liu, Z. Tian, P. Liu, J. Jiang, and Z. Li, "An Approach of Semantic Web Service Classification Based on Naive Bayes," in 2016 IEEE International Conference on Services Computing (SCC), San Francisco, CA, USA, Jun. 2016, pp. 356-362, doi: 10.1109/SCC.2016.53.

[3] N. L. Ratniasih, "Optimasi Data Mining Menggunakan Algoritma Nä̈ve bayes Dan C4.5 Untuk Klasifikasi Kelulusan Mahasiswa," J. Teknol. Inf. Dan Komput., vol. 5, no. 1, Feb. 2019, doi: 10.36002/jutik.v5i1.634.

[4] T. M. Butar, M. A. Fauzi, and Indriati, "Penentuan Rating Review Film Menggunakan Metode Multinomial Nä̈ve bayes Classifier dengan Feature Selection berbasis Chi-Square dan GalavottiSebastiani-Simi Coefficient," J. Pengemb. Teknol. Inf. Dan Ilmu Komput., vol. 3, pp. 447-453, 2019.

[5] F. Handayani and F. S. Pribadi, "Implementasi Algoritma Naïve bayes Classifier dalam Pengklasifikasian Teks Otomatis Pengaduan dan Pelaporan Masyarakat melalui Layanan Call Center 110," J. Tek. Elektro, vol. 7, pp. 19-24, Jun. 2015.

[6] M. Idris, "Implementasi Data Mining Dengan Algoritma Naïve bayes Untuk Memprediksi Angka Kelahiran," J. Pelita Inform., vol. 18, pp. 160-167, 2019.

[7] F. Gorunescu, Data Mining Concepts Models and Techniques, 1st ed., vol. 12. Craiova: Springer Berlin Heidelberg, 2011.

[8] M. Ridwan and H. Suyono, "Penerapan Data Mining Untuk Evaluasi Kinerja Akademik Mahasiswa Menggunakan Algoritma Naïve bayes Classifier," vol. 7, no. 1, p. 6, 2013.

[9] A. Saleh, "Implementasi Metode Klasifikasi Nä̈ve bayes Dalam Memprediksi Besarnya Penggunaan Listrik Rumah Tangga," vol. 2, no. 3, p. 11, 2015.

[10]T. R. Patil and M. S. S. Sherekar, "Performance Analysis of Naïve bayes and J48 Classification Algorithm for Data Classification," Open Access, vol. 6, p. 6, 2013.

[11]A. Powar and D. V. Ghorpade, "Heart Disease Prediction System Using Nä̈ve bayes Data Mining Technique," ICTACT J. SOFT Comput., pp. 1824-1830, 2018.

[12]T. B. Sasongko, "Komparasi dan Analisis Kinerja Model Algoritma SVM dan PSO-SVM (Studi Kasus Klasifikasi Jalur Minat SMA)," J. Tek. Inform. Dan Sist. Inf., vol. 2, no. 2, Aug. 2016, doi: 10.28932/jutisi.v2i2.476.

[13]M. Utmal and R. K. Pandey, "Taxonomy on the Integration of Hadoop and Rapid Miner for Big Data Analytics," in 2015 International Conference on Computational Intelligence and Communication Networks (CICN), Jabalpur, India, Dec. 2015, pp. 890-893, doi: 10.1109/CICN.2015.175.

[14]M. F. Rahman, D. Alamsah, M. I. Darmawidjadja, and I. Nurma, "Klasifikasi Untuk Diagnosa Diabetes Menggunakan Metode Bayesian Regularization Neural Network (RBNN)," J. Inform., vol. 11, no. 1, p. 36, Jan. 2017, doi: 10.26555/jifo.v11i1.a5452. 